\title{
ANALISIS PERTANDINGAN TIM BOLAVOLI PUTRI KABUPATEN SUMENEP PADA KEJUARAAN PROVINSI REMAJA TAHUN 2019 DI BANYUWANGI
}

\author{
Taufik Rahman ${ }^{1}$, Mohammad Hasan Basri² \\ 1,2 STKIP PGRI Sumenep \\ Email: opick_conk@stkippgrisumenep.ac.id1', hasanbasri1988@stkippgrisumenep.ac.id² \\ DOI: https://doi.org/10.36526/kejaora.v4i2.746
}

\begin{abstract}
ABSTRAK
Tujuan penelitian ini untuk mengetahui analisis hasil pertandingan tim putri Kabupaten Sumenep dalam Kejuaraan Provinsi Remaja tahun 2019 di Banyuwangi terutama dari segi teknik dasar dan keterampilan bermain. Hal ini bertujuan untuk perbaikan dari segi teknik dan keterampilan bermain untuk kejuaraan yang akan datang baik dari teknik dasar passing, smash, block, set up dan service. Hasil penelitian menunjukkan bahwa kesalahan yang sering dilakukan yaitu service sebesar 6,07 \%, receive sebesar 10,93\%, smash sebesar $15,38 \%$, block sebesar $23,88 \%$, dig sebesar $38,86 \%$, set up sebesar 4,85\%. Dalam penelitian ini dapat disimpulkan bahwa kesalahan yang sering dilakukan oleh pemain putri pada kejuaraan provinsi bolavoli tahun 2019 di Banyuwangi terutama pada saat defense. Antisipasi serangan dari lawan (dig) menjadi permasalahan utama dalam tim selain block, smash, receive, service dan set up.
\end{abstract}

Keywords: Service, Receive, Smash, Block, Dig, Set Up

\section{PENDAHULUAN}

Kabupaten Sumenep merupakan salah satu kabupaten yang memiliki klub bolavoli terbanyak se Indonesia, hal ini bisa dibuktikan dengan diraihnya rekor MURI karena banyaknya klub bolavoli yang ada di kabupaten ujung timur pulau Madura ini yang mecapai 600 klub. Segudang prestasi juga pernah diraih oleh tim bolavoli Kabupaten Sumenep baik di tingkat remaja, junior maupun senior. Hal ini tidak lepas dari banyaknya bibit potensial dan pembinaan atlet mulai dari tingkat remaja, senior dan junior. Bahkan, tim bolavoli kabupaten Sumenep selalu menyumbangkan atletnya untuk membela tim bolavoli Jawa Timur baik indoor maupun pantai.

\begin{tabular}{llr}
\multicolumn{4}{c}{ Usia remaja merupakan usia dimana } \\
anak memiliki kesempatan untuk \\
mengembangkan bakat dan minat
\end{tabular} olahraganya, di sinilah anak sudah memilih spesialisasi untuk ditekuni. Kegemaran mereka terhadap cabang olahraga bisa dikembangkan baik di sekolah melalui ekstrakurikuler maupun di klub nya masingmasing. Menurut (Akarcesme \& Aytar, 2018) usia relatif tidak memiliki pengaruh yang signifikan terhadap performa pemain bolavoli baik putra maupun putri di usia yang sama
(14-16 tahun). Artinya, kondisi fisik dan psikologis mereka masih labil dan mereka bisa melatihnya dengan memperbanyak latih tanding.

Tim bolavoli remaja Kabupaten Sumenep pernah berjaya di era nya. Pada tahun 2007, 2008 dan 2009 tim bolavoli remaja putra meraih juara 1 berturut - turut, tahun 2010 dan 2012 juara 3, namun tidak pada tim bolavoli remaja putri. Tim putri hanya mampu bersaing dengan tim dari kabupaten lain pada babak kedua. Pada era tersebut merupakan masa emas tim bolavoli remaja putra dan kabupaten Sumenep bisa mencetak sejarah dengan meraih juara 1 selama tiga kali berturut-turut. Pada tahun 2017, tim bolavoli remaja putri pertama kalinya berhasil melaju ke babak semifinal dan berhasil meraih juara ketiga pada Kejurprov Remaja tahun 2017 di Jombang. Namun pada tahun 2018, secara mengejutkan tim putri hanya mampu bertahan pada babak kedua setelah dikandaskan tim kabupaten Mojokerto dengan skor 3 - 2 pada Kejurprov Remaja tahun 2018 di Ngawi.

Seiring berjalannya waktu, klub bolavoli di Kabupaten Sumenep sudah mulai banyak berkurang, hal ini berdampak pada 
pembinaan potensi atlet di klub yang juga mulai berkurang. Akibatnya, atlet usia remaja semakin sedikit dan berpengaruh terhadap prestasi kabupaten Sumenep di tingkat Jawa Timur yang juga mulai merosot. Tim putra dan putri tidak mampu bersaing dengan tim dari kabupaten lain sehingga beberapa tahun kabupaten Sumenep puasa gelar di tingkat Jawa Timur. Namun, PBVSI Pengkab Sumenep memiliki terobosan untuk mengadakan pembinaan atlet jangka menengah dan jangka panjang. Hasil seleksi pada Kejuaraan Kabupaten tingkat Remaja dijadikan sebagai ajang untuk memilih bibit atlet potensial dari tiap klub yang berada di bawah kawedanan masing-masing, alhasil ada 18 pemain putri dan 20 pemain putra yang terjaring seleksi. Pembinaan kepada atlet yang terjaring seleksi tersebut berkisar 10 bulan menjelang kejuaraan provinsi. Pembinaan yang dilakukan lebih lama daripada pembinaan yang dilakukan sebelumnya diharapkan mampu mengangkat prestasi bolavoli di Sumenep. Hal ini sesuai dengan penelitian yang dilakukan oleh (Bilici \& Selcuk, 2018; Akarcesme \& Aytar, 2018) bahwa proses latihan yang dilakukan selama 10 minggu dapat meningkatkan kondisi fisik atlet perempuan usia $14-16$ tahun seperti power lompatan. Dalam 10 minggu tersebut, frekuensi latian yang dilakukan selama seminggu sebanyak tiga kali latian. Pemusatan latihan selama 10 bulan tersebut dilaksanakan di luar jam sekolah, jadwal latihan tim putri hari Jumat pukul 13.00 wib 15.00 wib dan hari Minggu pukul 07.00 wib 09.00 wib. sedangkan jadwal latihan untuk tim putra hari Sabtu pukul 15.00 wib - 17.00 wib dan hari Minggu pukul 09.00 wib - 11.00 wib. Kegagalan pada kejuaraan tahun sebelumnya dievaluasi secara besarbesaran, faktor kondisi fisik dan teknik dasar yang acapkali menjadi permasalahan mendasar pada atlet seperti passing, service, block, smash dan set up mendapat perhatian khusus untuk menghadapi kejuaraan tahun depan. Kelemahan pada passing yang sangat mencolok adalah atlet tidak bisa melakukan receive dengan baik sehingga tim tidak bisa menyusun serangan dan lawan dapat dengan mudah mendapat poin, juga kesalahan dalam mengantisipasi serangan lawan (dig). Kelemahan pada service yang nampak seperti service asal masuk dan mudah diterima oleh lawan akan membuat lawan dengan mudah menyusun serangan dan memperoleh poin. Kelemahan pada block terletak pada antisipasi untuk menghadang serangan cepat (quicker) dari lawan dan block berpasangan/kelompok yang masih mudah ditembus oleh smash lawan. Kelemahan pada smash tidak terlalu mencolok karena rata-rata atlet remaja putri memiliki smash yang bagus, hanya saja perlu diajarkan bagaimana melakukan cop. Kelemahan pada set up terletak pada penyajian bola kepada smasher yang kurang pas dikarenakan receive yang kurang bagus. Pada pemusatan latihan tersebut, atlet digembleng baik dari segi fisik, teknik, taktik, mental maupun strategi. Hasilnya sangat memuaskan, pada Kejurprov tingkat Remaja tahun 2019 di Banyuwangi, tim bolavoli remaja putri berhasil mencetak sejarah untuk pertama kalinya berhasil menembus babak final dan meraih juara kedua pada kejuaraan tersebut.

Pada Kejurprov Remaja tahun 2019 di Banyuwangi kemarin, penampilan atlet remaja putri kabupaten Sumenep sudah sesuai dengan harapan pelatih, namun ada banyak aspek aspek yang harus diperbaiki. Untuk itu peneliti mengangkat judul "Analisis Pertandingan Tim Bolavoli Remaja Putri pada Kejuaraan Provinsi tingkat Remaja tahun 2019 di Banyuwangi".

\section{METODE}

Jenis penelitian ini merupakan penelitian kuantitatif non-eksperimen (ex post facto) dengan pendekatan survei, dimana peneliti hanya meneliti gejala yang sudah terjadi dengan menggunakan alat untuk mengumpulkan data (Maksum A. , 2012).

Populasi dalam penelitian ini adalah tim bolavoli usia remaja pada pemusatan latihan Kabupaten Sumenep. Dalam pemilihan sampel, peneliti menggunakan purposif sampling yaitu pemilihan sampel berdasarkan pertimbangan peneliti atau pemilihan sampel dengan tujuan tertentu dan sesuai dengan karakteristik yang diinginkan oleh peneliti (Erman, 2009). Tujuan dan karakteristik sampel tersebut sesuai dengan tujuan penelitian yaitu tim bolavoli remaja putri yang mengikuti kejuaraan provinsi 
tingkat Remaja tahun 2019 di Banyuwangi dengan usia 15 tahun (kelahiran 2003).

\section{HASIL DAN PEMBAHASAN}

Dari lima pertandingan yang dilakukan oleh tim bolavoli putri Kabupaten Sumenep dari babak penyisihan melawan Kabupaten Sidoarjo, babak perdelapan final melawan Kota Batu, babak perempat final melawan Kabupaten Kediri, Babak Semifinal melawan Kabupaten Banyuwangi dan Babak Final melawan Kabupaten Tulungagung didapatkan data kesalahan yang dilakukan dari teknik dasar diantaranya service, receive, smash, block, dig dan set up seperti pada pemaparan tabel di bawah ini:

\begin{tabular}{clccccccc} 
& \multicolumn{7}{c}{ Tabel 1 Rekap Kesalahan Pemain Tiap Pertandingan } \\
\hline Pertandingan & \multicolumn{1}{c}{ Lawan } & Service & Receive & Smash & Block & Dig & Set up & Skor set \\
\hline $\mathbf{1}$ & Kab. Sidoarjo & 2 & 4 & 12 & 35 & 35 & 2 & $1-3$ \\
\hline $\mathbf{2}$ & Kota Batu & 11 & 15 & 14 & 16 & 44 & 7 & $3-2$ \\
\hline $\mathbf{3}$ & Kab. Kediri & 8 & 9 & 17 & 27 & 42 & 6 & $3-2$ \\
\hline $\mathbf{4}$ & Kab. Banyuwangi & 5 & 4 & 16 & 13 & 27 & 3 & $3-0$ \\
\hline $\mathbf{5}$ & Kab. Tulungagung & 4 & 22 & 17 & 27 & 44 & 6 & $1-3$ \\
\hline Jumlah & & $\mathbf{3 0}$ & $\mathbf{5 4}$ & $\mathbf{7 6}$ & $\mathbf{1 1 8}$ & $\mathbf{1 9 2}$ & $\mathbf{2 4}$ & $\mathbf{1 1 - 1 0}$ \\
\hline
\end{tabular}

Kesalahan - kesalahan tersebut lebih jelas dilihat pada diagram di bawah ini:

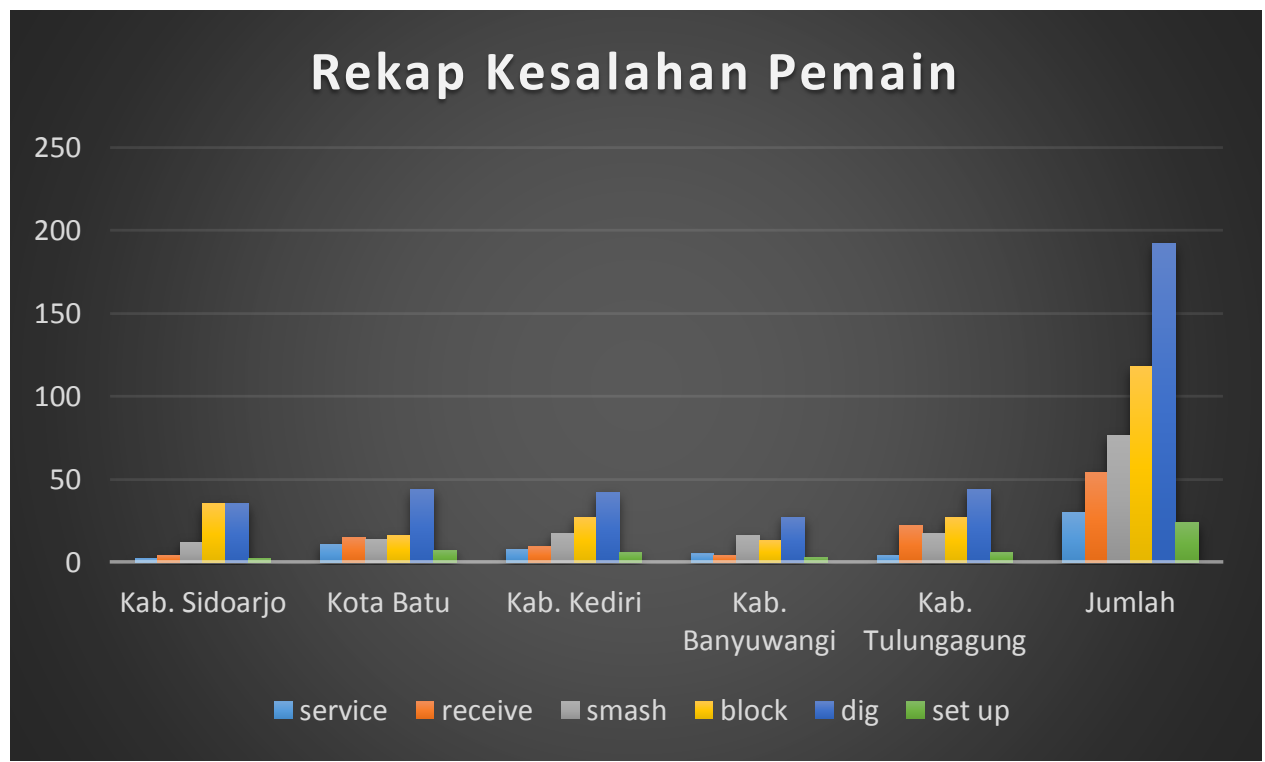

Gambar 1 Diagram Kesalahan Teknik Dasar

Berikut ini prosentase kesalahan yang dilakukan oleh tim bolavoli putri Kabupaten Sumenep dalam Kejuaraan Provinsi Bolavoli Remaja di Banyuwangi.

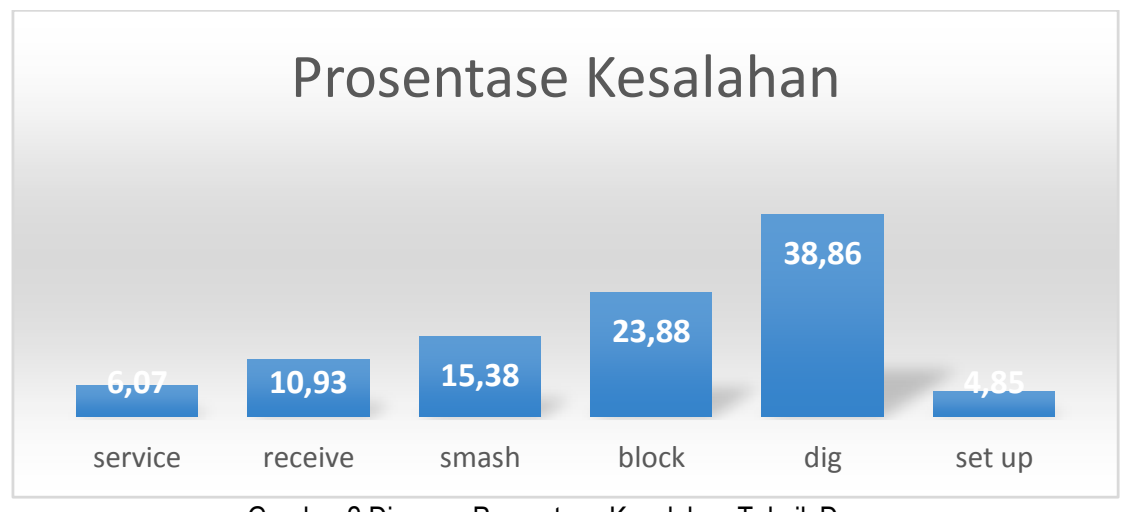

Gambar 2 Diagram Prosentase Kesalahan Teknik Dasar 
Dari data di atas kesalahan service sebesar $6,07 \%$, receive sebesar $10,93 \%$, smash sebesar $15,38 \%$, block sebesar 23,88 $\%$, dig sebesar $38,86 \%$, set up sebesar 4,85 $\%$. Kesalahan yang sering dilakukan pada saat dig (menerima serangan dari lawan), hal ini juga bisa disebabkan karena block yang kurang rapi dalam membendung seragan lawan.

\section{PEMBAHASAN}

Dari hasil analisis data yang sudah dilakukan oleh peneliti, dapat diketahui bahwa kesalahan yang sering dilakukan oleh pemain putri remaja PBVSI Kabupaten Sumenep pada saat dig (menerima serangan dari lawan), kesalahan dalam menerima serangan lawan terjadi karena kurangnya antisipasi terhadap bola dan ketidaksiapan pemain di dalam lapangan. Hal ini juga bisa disebabkan karena faktor block yang dilakukan kurang bagus sehingga mudah ditembus oleh serangan lawan. Block yang rapi dan bagus dapat dengan mudah membendung serangan lawan atau mengarahkan serangan lawan agar seorang digger dapat dengan mudah menerima serangan lawan.

Kesalahan berikutnya yang sering dilakukan yaitu kesalahan pada saat smash. Pemain sering melakukan kesalahan sendiri seperti smash out, smash tidak menyeberang net dan smash terhadang block lawan sehingga menghasilkan poin untuk lawan. Kesalahan pada saat receive terjadi karena antisipasi pemain terhadap bola hasil service kurang bagus, sehingga bola tidak dapat disajikan ke setter dengan baik. Receive yang bagus akan memudahkan setter dalam menyusun dan membuat pola serangan. Kesalahan pada service biasanya terjadi karena terburu - buru saat melakukan service, service out dan service tidak menyeberang net. Kesalahan pada saat set up terjadi karena bola tertahan (holding) atau penyajian bola kedua tidak sempurna (double) menyebabkan poin untuk lawan. Ada kalanya penyajian bola dari setter tidak jelas arahnya sehingga terjadi miss communication dengan smasher.

\section{KESIMPULAN}

Kesalahan yang sering dilakukan oleh pemain putri pada kejuaraan provinsi bolavoli tahun 2019 di Banyuwangi terutama pada saat defense. Antisipasi serangan dari lawan (dig) menjadi permasalahan utama dalam tim selain block dan receive. Defense yang kurang bagus menyebabkan lawan dapat memperoleh poin dengan mudah. Sehingga hal ini menjadi perhatian khusus dari pelatih agar dalam program latian, defense harus menjadi prioritas utama.

\section{DAFTAR PUSTAKA}

Akarcesme, C., \& Aytar, S. H. (2018). The Effect of Relative Age on Some Performance Characteristics in Young Volleyball Players. Journal of Education and Training Studies, 4348.

Bilici, O. F., \& Selcuk, M. (2018). Evaluation of The Effect of Core Training on the Leap Power and Motor Characteristic of the 14-16 years old Female Volleyball Players. Journal of Education and Training studies, 90-97.

Erman. (2009). Metode Penelitian Olahraga. Surabaya: Unesa University Press.

Maksum, A. (2009). Metodologi Penelitian. Surabaya: Unesa University Press.

Maksum, A. (2012). Metodologi Penelitian dalam Olahraga. Surabaya: Surabaya University Press. 